\title{
A instituição da reserva de vagas na universidade pública brasileira: os meandros da formulação de uma política
}

\author{
Guiomar de Oliveira Passos* \\ Marcelo Batista Gomes**
}

\section{Resumo}

Aborda-se o acesso ao ensino superior público no Brasil, delineando a instituição das cotas na Universidade Federal do Piauí em termos de motivações, objetivos e atores envolvidos. Objetiva-se caracterizar a experiência, enfatizando a inserção na agenda, o estabelecimento das alternativas de solução e a formulação da política. Para isso, baseia-se no modelo de Múltiplos Fluxos, em fontes documentais e entrevistas com o Reitor, relator do processo, procuradores, próReitores e presidentes da COPEVE. Constatou-se que esta foi uma iniciativa da administração superior estimulada pela expansão de vagas e pela exclusão dos egressos da escola pública nos cursos mais concorridos da Universidade. Portanto, a formulação dependeu do reconhecimento do problema e da existência de soluções viáveis e aceitáveis, demanda e clima político favorável; e, principalmente, de agentes dispostos a agir visando a sua concretização .

Palavras-chave: Educação Superior. Escola Pública. Análise de política pública. Reserva de Vagas.

\section{Introdução}

Este estudo é parte dos resultados da dissertação de mestrado intitulada "As cotas na Universidade Federal do Piauí: instituição e resultados" e versa sobre o acesso ao ensino superior público no Brasil. Focaliza-se a instituição das cotas na Universidade Federal do Piaú, identificando as motivações, objetivos e atores envolvidos na formulação.

*Doutorado em Sociologia pela Universidade de Brasília (2003). Professora associada da Universidade Federal do Piauí.

** Mestrado em Políticas Públicas (2013) pela Universidade Federal do Piauí. Professor do Ensino Básico do Instituto Federal do Piauí - IFPI 
Os egressos da escola pública, como foi constatado em pesquisas anteriores (PASSOS, 2007; 2009), até então, eram minoria entre os inscritos - 34,5\% dos candidatos - e entre os aprovados - 19\%. Por conseguinte, operava-se uma primeira seleção: a autoexclusão. Isso podia decorrer tanto da falta de acesso ao ensino médio ${ }^{1}$, como das escassas chances objetivas de sucesso, pois tinham chance de ocupar 809 vagas, enquanto os egressos da escola privada, 1.138 vagas; ou seja, tinham $1 \frac{1}{2}$ vezes menos chances do que estes.

Isso ocorre porque o acesso ao ensino superior no Brasil, principalmente em universidades públicas, tem sido, historicamente, um privilégio de poucos em que as classes privilegiadas ficam com as melhores vagas nas melhores instituições. Segundo Pinto (2004), o modelo de expansão adotado desde a Reforma Universitária de 1968 (Lei no 5.540/68) resultou em "uma grande elitização do perfil dos alunos, em especial nos cursos mais concorridos e nas instituições privadas, onde é muito pequena a presença de afrodescendentes e de pobres" (PINTO, 2004, p. 727). Isso porque, primeiro, como mostram os dados do IBGE (2010), há dificuldade de acesso ao ensino médio: a taxa de escolarização líquida, analisada pelos quintos do rendimento mensal familiar per capita, revela que, enquanto no primeiro quinto (os $20 \%$ mais pobres), somente $32 \%$ dos adolescentes de 15 a 17 anos de idade estavam no ensino médio, no último quinto ( $20 \%$ mais ricos), essa oportunidade atingia quase $78 \%$.

Outro fator, como evidenciado em estudo do Observatório Universitário da Universidade Cândido Mendes, citado por Ristoff e Pacheco (2004, p. 9), é a carência: " $25 \%$ dos potenciais alunos universitários são tão carentes que não têm condições de entrar no ensino superior, mesmo se ele for gratuito". O percentual destacado, segundo Ristoff e Pacheco (2004), representava, naquela ocasião, 2,1 milhões de estudantes que necessitavam, para serem incluídos no sistema de ensino superior, mais do que da gratuidade, ações que garantissem bolsas de estudo, trabalho, monitoria, extensão, pesquisa, restaurantes universitários subsidiados, moradia estudantil, ou outras formas que, combinadas a essas, tornassem viável a sua permanência na instituição.

As instituições públicas de ensino superior, no escopo de sua autonomia, desde 2002, vinham estabelecendo mecanismos favorecedores do acesso

1 No Piauí, em 2005, a taxa de escolarização líquida, nesse nível de ensino, era de 22,4\% e a bruta 76,5\% (INEP, 2006). 
para os grupos menos privilegiados, destinando-lhes vagas específicas, as chamadas cotas. Estas, segundo o Instituto de Pesquisa Avançada em Educação, significam a criação de "reserva de vagas em instituições públicas ou privadas para determinados segmentos sociais" (IPAE, 2010, p.1). Considera-se, segundo o Instituto, uma forma de "ação afirmativa"( IPAE, 2010, p.1), algo para reverter o racismo histórico contra determinadas classes étnicas, conforme conceito surgido nos Estados Unidos na década de 1960. No ensino superior brasileiro, até a aprovação da lei $\mathrm{n}^{\circ} 12.711$, de 29 de agosto de 2012, que uniformizou a medida nas instituições federais de ensino superior, havia diversos modelos de cotas (raciais, étnicas, socioeconômicas e cotas para egressos da escola pública).

A Universidade Federal do Piauí instituiu a reserva de vagas, em 2006, pela Resolução 093/06-CEPEX. Primeiramente, eram 5\%, depois, 20\%, pela Resolução 138/08-CEPEX, em todos os cursos para os candidatos que realizaram a Educação Básica (ensino fundamental e ensino médio) integralmente em escola pública. Desse modo, é uma ação que integra os dois níveis da educação oferecidos pelo Estado - o básico e o superior.

Analisa-se essa experiência, examinando como foi tomada a decisão de implementá-la em 2006, os fatores que influenciaram e quais eram os objetivos e metas. Por conseguinte, volta-se para uma política pública, examinando sua conformação, tendo por base o modelo de Múltiplos Fluxos (Multiple Streams Model), desenvolvido por John Kingdon (CAPELLA, 2006, p. 25) que, dentre os processos de formação das políticas públicas, enfatiza os estágios pré-decisórios; isto é, a formação da agenda e o estabelecimento das alternativas de solução.

A agenda, segundo Capella (2006, p. 26), a partir de Kingdon, é "o conjunto de assuntos sobre os quais o governo e pessoas ligadas a ele concentram sua atenção num determinado momento". Em outras palavras, é o reconhecimento de que determinados assuntos carecem de uma ação estatal. Seu estabelecimento, primeiro processo de uma política pública, de acordo com o modelo, pode ocorrer tanto em face do conhecimento do assunto - estatísticas, relatórios da execução de políticas, por exemplo - como do agravamento de determinadas situações (CAPELLA, 2006; GOMIDE, 2008). A estes elementos, junta-se a precisão de sua definição em termos do que o provoca ou possibilita a sua solução. 
O segundo processo de uma política pública é relativo às alternativas e soluções. Estas, conforme Gomide (2008, p. 8), apresentadas por especialistas da comunidade técnico-científica, são selecionadas a partir de "critérios de viabilidade técnica, financeira (custos toleráveis) e política (aceitação pública), de acordo com o momento e o contexto". A escolhida é difundida, sendo levada pelos especialistas a diferentes fóruns, de modo a sensibilizar não apenas os geradores de soluções, como também o povo em geral, a fim de ampliar a consciência sobre determinada ideia.

Sem a difusão, diz Capella (2006, p. 28), "as propostas não serão seriamente consideradas quando apresentadas" já que precisam de simpatizantes ou adeptos para serem escolhidas e isso depende de que as ideias sejam compartilhadas por um número maior de pessoas. Tem-se, assim, que as ideias são partes "integrais do processo decisório dentro e em torno do governo" (KINGDON, 2003 apud CAPELLA, 2006, p. 27), sendo mais importantes do que os grupos de pressão.

O terceiro processo é relativo à dimensão política, à constituição das coalizões e às barganhas e negociações. Consiste no processo político propriamente dito, importando a partilha da situação por diversas pessoas, por algum tempo, incentivando ou desestimulando determinadas questões ou ideias, bem como as "forças políticas organizadas, exercidas principalmente pelos grupos de pressão" e as mudanças dentro do governo. Este, conforme Gomide (2008, p. 8), "é determinante" para um problema entrar na agenda.

Assim, a formulação de uma política pública depende de que esta se torne um problema reconhecido, de que existam soluções viáveis e aceitáveis, bem como de demanda e clima político para a sua solução. A articulação desses três processos ou fluxos requer, segundo Gomide (2008, p. 9), "pessoas dispostas a investir seus recursos numa ideia ou projeto visando à sua concretização"; são, em sua expressão, os "empreendedores da política", encontrados, explica $\mathrm{o}$ autor, "dentro dos governos (dirigentes, burocratas, servidores de carreira) e na sociedade civil (lobistas, acadêmicos, jornalistas)". Alguns vão influenciar na definição da agenda, outros nas decisões e nas escolhas; os primeiros são visíveis, enquanto os outros são invisíveis.

Os atores visíveis recebem atenção da imprensa e do púbico e exercem influência, em maior ou menor grau, sobre a agenda governamental. Os participantes 
invisíveis têm influência predominante sobre a geração das alternativas e soluções. Esse é o grupo composto por servidores públicos, analistas de grupos de interesse, assessores parlamentares, acadêmicos, pesquisadores e consultores. Os primeiros atuam na definição do que entra, ou não, na agenda, pois participam dos fluxos de problemas e de políticas, que são os principais meios de acesso à agenda governamental, enquanto os outros participam na escolha de alternativas, atuando principalmente na agenda de decisão, na definição das alternativas.

O texto utiliza-se de abordagem qualitativa, valendo-se de pesquisa documental e entrevistas. A primeira abrangeu os documentos elaborados durante a discussão e aprovação da medida (atas, pareceres e resoluções), e notícias e artigos publicados em jornais sobre a proposição, aprovação, formulação e atores envolvidos em cada uma das etapas.

As entrevistas envolveram os atores "visíveis" e os "invisíveis" no processo de formulação da política pública. Os primeiros foram o então Reitor Luiz de Souza Santos Júnior e o relator do processo professor Francisco Newton Freitas. Os demais são aqueles que participaram na geração das alternativas e soluções, como procuradores, o pró-Reitor de assuntos estudantis da época $(2006,2008)$ Professor Fernando Aécio de Amorim Carvalho e os presidentes da COPEVE, em 2006, Professor José Alberto Lemos Duarte e, em 2008, Professor Saulo Cunha Serpa Brandão.

Com as entrevistas, procurou-se apreender as motivações para a proposição da medida, o reconhecimento do problema - dados e informações - sobre o acesso ao ensino superior, em particular dos egressos da educação básica pública, as razões da escolha dos egressos da educação básica pública, os posicionamentos favoráveis e contrários à medida, as ações assistenciais e a percepção dos gestores sobre uma política pública que integra os dois níveis da educação oferecidos pelo Estado: o básico e o sistema de ensino superior.

Os resultados estão organizados em quatro seções, incluindo esta introdução, que é a primeira. A segunda, Reserva de vagas como estratégia de acesso ao ensino superior, trata do panorama da instituição das cotas nas universidades públicas brasileiras. A terceira, A formulação da política de cotas na UFPI, discorre sobre a institucionalização da reserva de vagas na UFPI, em 2006, focalizando a inserção 
da problemática do acesso na agenda de decisões da UFPI, os atores envolvidos, as motivações e as resistências em torno da proposta de política de cotas apresentada para a Instituição. Nas considerações finais, analisa-se a inclusão na agenda, alternativas de solução e embates e expondo alguns resultados.

\section{Reserva de vagas como estratégia de acesso ao ensino superior público}

As ideias de favorecimento aos desfavorecidos fazem parte das lutas contra as discriminações desde o século XVIII. Algumas vezes, corporificaram-se em medidas antissegregacionistas, outras, em reserva de determinada parte de um todo para grupos específicos. Uma e outra têm sido chamadas de ações afirmativas, no sentido de que, nos termos de Bittar e Almeida (2006, p. 144), "um 'projeto de reparações", pois têm em vista inserir tradicionais excluídos em determinados contextos. Esse é o sentido do inciso VIII do Art. 37 da Constituição de 1988, depois regulamentado pela Lei $\mathrm{n}^{\circ}$ 8.112/90, ao estabelecer reserva "de cargos e empregos públicos para as pessoas portadoras de deficiência” (BRASIL, 1990).

No ensino superior, a reserva de vagas é inaugurada, no Brasil, pelo estado do Rio de Janeiro, em 2000, com a aprovação da Lei Estadual no 3.524/2000, de 28 de dezembro de 2000 , que estabelecia a reserva de $50 \%$ das vagas das universidades do estado do Rio de Janeiro e da Universidade Estadual do Norte Fluminense (UENF) para estudantes das redes pública municipal e estadual. Depois, em 2001, "a Lei Estadual $\mathrm{n}^{\circ} 3.708$ determinou a reserva de $40 \%$ do total de vagas dessas duas universidades para quem se declara negro ou pardo" (BRANDÃO, 2005, p. 62).

Essas iniciativas desencadearam outras semelhantes na Universidade do Estado da Bahia (UNEB), e na Universidade de Brasília (UnB), ao destinarem, respectivamente, $40 \%$ e $20 \%$ das vagas para candidatos que se declarassem negros. A medida era adotada, ora por leis, caso das instituições estaduais, ora no caso das federais, por determinação dos Conselhos Superiores, ou baseadas nas próprias leis de criação, como na Universidade Federal do ABC (UFABC), e na Universidade Federal do Recôncavo Baiano.

No Piauí, as duas universidades públicas - Universidade Federal do Piauí e Universidade Estadual do Piauí - enquadram-se nesse último caso, adotando a 
medida por determinação dos seus colegiados superiores. A primeira, em 2006, reservava 5\% para egressos da educação básica pública, e a segunda, em 2009, $10 \%$ também para egressos da educação básica pública, das quais $50 \%$ para aqueles que se autodeclarassem negros.

As tentativas de regulamentação foram diversas. Projetos de Lei $-\mathrm{n}^{\circ}$ 73/1999, no 3.198/2000 e 3.913/2008, o Estatuto da Igualdade Racial — foram apresentados, objetivando instituir o sistema nas instituições federais de educação profissional, tecnológica e superior, mas todos foram arquivados. Isso implicou em diferentes experiências, ainda que todas motivadas a tornar o ensino superior acessível a setores da população que, em face de problemas raciais, étnicos ou socioeconômicos, eram eliminados ou tinham entrada dificultada. Isto é, essas experiências desejavam impedir que os processos seletivos tivessem por base unicamente as capacidades intelectuais do candidato.

A medida, especialmente quando o critério é racial, tem gerado polêmica. Para os contrários a ela, fere o princípio da igualdade política e jurídica dos cidadãos, fundamento essencial da República e um dos alicerces da Constituição e, no caso das raciais, introduziria o racismo no país, institucionalizando direitos a partir da cor da pele, ou a desvalorização da diversidade como processo integrador da humanidade.

Para os que são favoráveis, as cotas possibilitam, primeiramente, cumprir o dispositivo constitucional de erradicação da pobreza e de redução das desigualdades sociais e regionais e, posteriormente, saldar a enorme dívida social da nação para com pobres, negros, pardos e índios, sendo um modo de aumentar suas presenças nas instituições públicas, principalmente nos cursos mais concorridos.

A população tem apoiado a medida: $65 \%$, quando as cotas são raciais, e $87 \%$, quando socioeconômicas - segundo dados do Instituto Data Folha, citados por Queiroz e Santos (2006, p. 718). Nos julgamentos de ações impetradas contra sua implementação em instituições federais de ensino, também o Supremo Tribunal Federal manifestou-se a favor, considerando-a não apenas uma "providência adequada" como proporcional, pois, conforme o relator, o Ministro Ricardo Lewandowski, "a política de ação afirmativa adotada pela Universidade de Brasília não se mostra desproporcional ou irrazoável, afigurando-se também sob esse ângulo compatível com os valores e princípios da Constituição" (BRASIL, 2012b). Esta, arrematou o então presidente da Corte, Ministro Ayres Britto, 
"legitimou todas as políticas públicas que buscam promover setores sociais desfavorecidos pela história. São políticas afirmativas do direito de todos os seres humanos a um tratamento igualitário e respeitoso. Assim é que se constrói uma nação" (BRASIL, 2012b).

Apesar da celeuma, expandiram-se. Até 2012, segundo estudo da ONG Educafro (2012), mais de 180 instituições de ensino superior no Brasil adotavam reserva de vagas ou sistema de bônus em seus processos seletivos, e consolidaram-se com a aprovação da Lei $n^{\circ}$ 12.711, em 29 de agosto de 2012. Esta, se não pôs fim ao debate, estabelece um padrão entre as diversas instituições federais ao determinar, no Art. $1^{\circ}$, a reserva de, "em cada concurso seletivo para ingresso nos cursos de graduação, por curso e turno, no mínimo 50\% (cinquenta por cento) de suas vagas para estudantes que tenham cursado integralmente o ensino médio em escolas públicas" (BRASIL, 2012a). Para o preenchimento das vagas de que trata este artigo, 50\% (cinquenta por cento) deverão ser reservadas aos estudantes oriundos de famílias com renda igual ou inferior a 1,5 salário-mínimo (um salário-mínimo e meio) per capita.

A instituição da medida na UFPI é o que se expõe a seguir.

\section{A formulação da política de cotas na UFPI}

A Universidade Federal do Piaú foi pioneira na implementação de um sistema de reserva de vagas no Estado. A medida foi instituída, em 2006, pela Resolução 093/06-CEPEX, reservando 5\% das vagas, em todos os cursos, aos candidatos que realizaram a Educação Básica (ensino fundamental e ensino médio) integralmente em escola pública. Em 2008, pela Resolução 138/08-CEPEX, este percentual foi alterado para $20 \%$. Por conseguinte, os critérios não foram étnicos, raciais ou socioeconômicos, mas o tipo de escola, integrando o ensino superior ao básico.

Nesse momento, a expansão do acesso ao ensino superior já havia sido incorporada à agenda do Estado brasileiro, sendo um dos objetivos do Plano Nacional de Educação para o período de 2001 - 2011. Ali, consignou-se prover, "até o final da década, a oferta de educação superior para, pelo menos, 30\% da faixa etária de 18 a 24 anos" e a ampliação da "oferta de ensino público de modo a assegurar uma proporção nunca inferior a $40 \%$ do total das vagas, prevendo inclusive a parceria da União com os estados na criação de novos estabelecimentos de educação superior" (BRASIL, 2001, p. 43). 
Também já era uma prioridade governamental, sendo uma das ações previstas no Plano Plurianual 2004-2007, primeiro do Governo Lula, através do programa Universidade do Século XXI com um aporte de recursos de R $\$$ 13.431.288.372,00 (BRASIL, 2008, p. 748), que correspondia, conforme o Relatório de Avaliação do Plano Plurianual 2004-2007 - MEC (BRASIL, 2008, p. 689), a 57,7\% daqueles destinados aos programas sob a responsabilidade do Ministério da Educação. Essa era a maior parcela.

A UFPI, conforme nota publicada no Jornal O Dia (FERNANDES, 2005), inseriu-se nesse processo em dezembro de 2005, assinando, junto de outras 13 instituições federais, convênios para expandir sua oferta que, conforme a mesma fonte, só na primeira etapa, "previa a liberação imediata de 10 milhões de reais, para contratação de servidores técnicos administrativos e professores e investimentos em infraestrutura" o que, consoante o então Reitor, significava "dobrar de dois para quatro o número de campi, com a criação de mais 19 novos cursos e abertura de 1.700 vagas" (FERNANDES, 2005, p. 3).

Desse modo, favorecia o acesso, inclusive para aqueles não residentes na capital, o que era, segundo o Plano Plurianual 2003-2007, uma das prioridades do governo (BRASIL, 2003, p. 80). É parte desse esforço, ainda, a adesão ao projeto "Universidade Aberta", que previa uma oferta inicial de 500 vagas na modalidade educação à distância (UNIVERSIDADE..., 2006, p. 2).

A alteração do sistema de ingresso na Universidade Federal do Piauí inicia-se em 9 de maio de 2006, quando o presidente da Comissão Permanente de Seleção - COPESE da Universidade Federal do Piauí, à época Comissão Permanente de Concurso Vestibular - COPEVE, Prof. José Alberto Lemos Duarte, através do Processo n 23111.006484/06-81 solicita a atualização da Resolução 077/00-CEPEX, que normatizava o Processo Seriado de Ingresso na Universidade - PSIU. A providência era necessária, diz o documento, em face da implantação de dezenove novos cursos, em decorrência do Programa de Expansão da UFPI (UFPI, 2006a, p. 2).

O pedido restringia-se à " mudança $[. .$.$] no modo de escrever a Fórmula de$ cálculo dos Escores Padronizados dos candidatos” (UFPI, 2006a, p. 2-4), não apresentando qualquer proposta relativa a um sistema de reserva de vagas. $\mathrm{O}$ Art. $1^{\circ}$ da minuta da Resolução $n^{\circ}$ 93/06 (Processo $n^{\circ}$ 23.111.006484/06-81) é explícito quanto à manutenção do antigo processo: 
$\mathrm{O}$ ingresso nos cursos de graduação da Universidade Federal do Piauí, tal como tem ocorrido a partir do ano de 2004, far-se-á através de processo seletivo seriado, realizado anualmente, destinado à classificação de candidatos, através da avaliação do seu desempenho, em exames correspondentes a cada uma das séries do Ensino Médio, de acordo com o disposto nesta Resolução (UFPI, 2006a).

O relator da matéria na $251^{\mathrm{a}}$ reunião do Conselho de Ensino, Pesquisa e Extensão, Professor Francisco Newton Freitas, então Pró-Reitor de Ensino de Graduação, também não faz menção à reserva de vagas no parecer em que aprova a proposição (UFPI, 2006b, p. 40). O tema surge no encerramento da reunião, quando, conforme Ata, o então Reitor, Professor Luiz de Sousa Santos Júnior, solicita que os conselheiros pensem "numa alternativa quanto ao peso específico para Escola Pública, como forma de incentivo aqueles alunos" (UFPI, 2006b, p. 67, grifo nosso).

Segundo os registros das atas das reuniões $251^{\mathrm{a}}$ e $252^{\mathrm{a}}$ do CEPEX, a Reitoria estava incomodada com o baixo acesso dos alunos egressos das escolas públicas na UFPI, principalmente naqueles cursos mais concorridos. Para garantir que, efetivamente, os egressos destes ingressem no ensino superior, a UFPI teria, segundo o Reitor, de elaborar uma proposta de reserva de vagas que lhes favorecesse. Diferentemente do que dizem os críticos, ele complementa, isso não legitimaria o fracasso escolar das escolas públicas; ao contrário, seria um instrumento de fortalecimento. Além disso, a Universidade mostraria para a sociedade que "está preocupada com a visão sistêmica da educação desde os seus primeiros pilares, para poder garantir ao aluno de escola pública oportunidade igualitária" (UFPI, 2006b, p. 70).

Os egressos de escolas públicas, conforme disse em entrevista à pesquisa o Professor Francisco Newton Freitas, à época Pró-Reitor de Ensino de Graduação, não tinham acesso aos cursos mais concorridos. "Em Medicina, há mais de vinte anos não entrava um aluno de escola pública". O Reitor Luiz Júnior, baseado em estudo realizado pela COPEVE, em 2006, corrobora essa análise dizendo na entrevista à pesquisa:

os alunos das escolas públicas perdiam o PSIU, isto é, não obtinham pontos suficientes para serem classificados. Daí a ideia de 
provocar o CEPEX a discutir a situação e, consequentemente, buscar uma solução. Afinal, esses alunos, por razões que lhes escapavam, estavam sendo preteridos nos melhores cursos de nossa Universidade.

As discussões foram objeto de duas reuniões do CEPEX, a $252^{\mathrm{a}}$ e a $253^{\mathrm{a}}$. As várias manifestações registradas nas Atas gravitaram em torno de como facilitar o acesso dos alunos egressos de escolas públicas, na UFPI, para que ingressassem nos cursos mais concorridos, depois, nas ações necessárias para assegurar a permanência dos beneficiados. $\mathrm{O}$ conselheiro-relator, Francisco Newton Freitas, pronunciou-se chamando a atenção para a complexidade do problema. Em sua visão, a solução para a baixa frequência de alunos egressos de escolas públicas, no ensino superior público, tinha como causa o fracasso da escola que frequentaram. Todavia, "a política de cota para aluno de escola pública, no vestibular da UFPI, já seria de bom alvitre, constituindo-se um avanço bastante significativo" (UFPI, 2006c, p. 71).

O conselheiro Charles Carvalho Camillo da Silveira, por sua vez, partilhava desse entendimento, reiterando que fossem definidas "formas de acesso ao ensino superior" que promovessem "uma verdadeira democratização" com "uma política afirmativa" nos parâmetros definidos na legislação (UFPI, 2006c, p. 71). O conselheiro Luiz Evaldo de Moura Pádua concordou com o colega, argumentando que "existe ainda aqueles cursos considerados "vitrine" cujo acesso, em face da concorrência, requer melhor preparação (UFPI, 2006c, p. 72).

O presidente da COPEVE, José Alberto Lemos Duarte, corroborou a afirmação do conselheiro Luiz Evaldo, acrescentando, com base no perfil socioeconômico traçado a partir do questionário aplicado pela COPEVE, que é raro um aluno que frequentou a escola básica pública lograr êxito no vestibular para os cursos mais concorridos. Para se ter uma ideia, diz, "no [...] de Medicina, por exemplo, o último candidato classificado" tem nota superior aos primeiros classificados de muitos cursos. Isso, segundo ele, "mostra a distância do aluno da escola pública dos alunos das escolas particulares” (UFPI, 2006c, p. 72).

O Reitor Luiz Júnior observou que isso não ocorre apenas em relação ao curso de Medicina, ainda que nesse seja maior a desigualdade, mas também nos cursos mais concorridos, como Direito, Serviço Social e Nutrição. Isso em 
uma realidade como a piauiense, em que os pobres são mais de 3 quartos da população. A Universidade, ele disse, "tem que fazer a sua parte para minorar essa situação". É preciso, completou, "“quebrar o tabu", possibilitando que os alunos de escola pública ingressem "nos cursos nobres da UFPI" (UFPI, 2006c, p. 74) e, com isso, diminuir a desigualdade.

O representante dos discentes no CEPEX, conselheiro Bruno de Carvalho Sena, por seu turno, ratificou essa análise falando da dificuldade dos alunos da escola pública concorrerem, em particular nos cursos da área de saúde, com os egressos de escolas privadas. Assim, diz Bruno Sena,

sem a adoção dessa medida, cada vez mais esses alunos se distanciarão dos cursos considerados de 'elite', o que explica, haver todo ano em nossa Universidade, grande demanda de alunos carentes engrossando a maioria dos cursos de licenciatura, onde a concorrência é bem menor, caracterizando-se, cada vez mais o aumento das desigualdades sociais (UFPI, 2006c, p. 73).

Para ele, uma universidade pública deveria, primeiramente, contemplar os alunos de escolas públicas, não os de escolas particulares, como vem ocorrendo. Para o conselheiro Antônio Silva do Nascimento, Vice-Reitor, o problema da falta de acesso ao ensino superior dos estudantes de escolas públicas estava no ensino médio. Os debates, então, foram relacionados às causas das dificuldades de acesso ao ensino superior público daqueles que frequentam a escola pública básica do que à reserva de vagas, seu escopo e beneficiados, não havendo questionamentos quanto à sua adoção, à sua abrangência e aos critérios de concessão.

Assim, não houve manifestações contrárias à sua adoção, também não se cogitaram, como já havia em outras instituições federais, as cotas raciais ou étnicas, nem ventilou-se a inclusão, por exemplo, daqueles que frequentaram escolas filantrópicas ou privadas através de bolsas de estudo, nem a redução da extensão da escolaridade exigida, por exemplo. Discutiu-se apenas a realização do ensino básico em escolas públicas.

As propostas apresentadas, ao longo do debate, foram as seguintes:

- Incluir a condição de egresso da escola pública como critério de desempate — apresentada pelo conselheiro Antônio José Gomes; 
- "Destinar o percentual de 5\% das vagas em cada curso, de forma linear, aos alunos que estudaram em escola pública, desde a educação infantil ao Ensino Médio, com a devida comprovação desse percurso" (UFPI, 2006c, p. 70) $3 / 4$ apresentada pelo Reitor. A medida, conforme a Ata da reunião, seria implementada ainda em 2006 para o ingresso dos alunos a partir do $1^{\mathrm{o}}$ semestre letivo de 2007, e teria prazo de validade determinado, ao fim do qual seria avaliada;

- "Definir formas de acesso ao Ensino Superior, fazendo uma verdadeira democratização desse acesso, através de uma política afirmativa, que pode e deve ser estabelecida sem ferir a legislação" (UFPI, 2006c, p. 71) 3/4 defendida pelo conselheiro Charles Carvalho Camillo da Silveira.

Algumas sugestões, é verdade, sequer foram discutidas; seus autores, rapidamente, como os conselheiros Antonio José Gomes, Newton Freitas e Charles Camillo da Silveira, juntaram-se ao Reitor, apoiando sua proposta. O fato é que a proposta do Reitor, de reservar vaga para alunos de escola pública, foi defendida por todos.

A proposta submetida à votação, segundo a Ata da $252^{\mathrm{a}}$ Reunião, foi apresentada nos seguintes termos:

Adotar o teto de 5\% (cinco por cento) de cota, para aluno de escola pública, linearmente, para todos os cursos neste vestibular (2007), desde que, comprovadamente atestem a sua proveniência da escola pública, durante toda a trajetória de vida escolar, isentando-os do pagamento da taxa de inscrição do Vestibular (UFPI, 2006c, p. 74).

A medida, segundo os registros da reunião, vigoraria por dois anos, ao fim dos quais seria avaliada e, dependendo dos resultados, seria ampliada com um percentual maior de vagas. Era, ainda segundo a Ata, "uma política diferenciada" no país demandando da Pró-reitoria de Assuntos Estudantis e Comunitários PRAEC providências para que os beneficiados fossem assistidos (UFPI, 2006c, p. 74). A reserva de vagas que o CEPEX estava aprovando, acrescenta o Reitor, segundo a Ata, "era uma política da UFPI", e esta adotaria meios de facilitar a permanência desses alunos no ensino superior, aprimorando sua política de assistência estudantil (UFPI, 2006c, p. 74). 
As ações necessárias para assegurar a permanência dos beneficiados constituíram a segunda preocupação dos conselheiros. Consta em Ata que o conselheiro Antonio José Gomes pronunciou-se propondo que a Universidade estabelecesse "uma política interna de condições e critérios para garantir a permanência desses alunos classificados nos cinco por cento, na UFPI, durante a realização do curso" (UFPI, 2006c, p. 70). Para o conselheiro Charles Carvalho Camillo da Silveira, a medida era imprescindível, do contrário de nada adiantaria a reserva de vaga. A Instituição, ele disse, tinha que estabelecer formas de acompanhar e apoiar esse aluno, "senão a evasão será cada vez maior" (UFPI, 2006c, p. 72).

Verifica-se que, para os conselheiros, as condições econômicas, sociais e culturais dos egressos das escolas públicas não apenas dificultavam o acesso, como poderiam comprometer a permanência daqueles favorecidos com a reserva de vagas, por isso propugnavam que a medida fosse acompanhada de ações que assegurassem a permanência. Daí a aprovação unânime da proposta do Reitor de que a UFPI, através da PRAEC (Pró-reitoria de Assuntos Estudantis e Comunitários), adotasse meios favorecedores da permanência, como ação complementar à reserva das vagas nos processos seletivos.

As decisões foram louvadas pelo conselheiro Antônio Silva do Nascimento, à época vice-Reitor, ressaltando, segundo a Ata da $252^{\mathrm{a}}$ Reunião, que a medida possibilitaria o ingresso de cerca de 150 alunos, o que significa que se tinha clareza das controvérsias que envolvia, inclusive sobre sua constitucionalidade e da necessidade de buscar meios de legalizá-la (UFPI, 2006c, p. 75).

A admoestação não esmoreceu o Colegiado. $\mathrm{Na}$ reunião seguinte $\left(253^{\mathrm{a}}\right.$ Reunião), cuidou-se da sistematização das decisões com a votação de cada item da minuta de Resolução cujo caput, conforme indicação do conselheiro Charles Carvalho Camillo da Silveira, teria a seguinte redação: "Normatiza o Programa de Ingresso na Universidade - PSIU, estabelece cotas para alunos oriundos integralmente de escola pública, isenta de taxas e define elementos da Política Interna de Permanência para os cotistas" (UFPI, 2006d, p. 76).

O texto final da Resolução no 93/06-CEPEX é o seguinte:

Art. $1^{0}$ Aprovar as normas que regulamentam o Programa Seriado de Ingresso na Universidade (PSIU), conforme anexo único. 
Art. $2^{\circ}$ Estabelecer o percentual de 5\% (cinco por cento) das vagas de cada curso oferecido pela Universidade Federal do Piauí (UFPI), objeto de seleção de graduados através do PSIU (modalidade presencial), destinadas para candidatos que tiveram a vida escolar básica (ensino fundamental e médio), integralmente, em escola pública.

Art. $3^{\circ}$ Conceder isenção da taxa de inscrição em qualquer etapa do PSIU (modalidade gradativa ou geral) para os $5 \%$ (cinco por cento) dos candidatos selecionados às vagas que tiveram a vida escolar básica (ensino fundamental e médio), integralmente, em escola pública.

Art. $4^{\circ}$ Estabelecer uma política interna de condições e critérios para garantir a permanência dos alunos cotistas classificados nos 5\% (cinco por cento) das vagas, na Universidade Federal do Piauí, durante toda a realização do curso.

Parágrafo único. A política de permanência será proposta num prazo de 30 (trinta) dias, a ser aprovada pelo Conselho de Ensino, Pesquisa e Extensão (CEPEX), em observância aos seguintes aspectos: transporte, alimentação, residência universitária, material didático, internet, apoio didático-pedagógico, bolsa saúde, dentre outros benefícios (UFPI, 2006e).

Este desenho, pelo que apurou-se nos documentos, resultou apenas dos debates no Conselho de Ensino, Pesquisa e Extensão.

Mesmo nos jornais, ainda que houvesse interesse pela temática abordada inclusive em cadernos especiais (COTAS..., 2005, p. 3-5), não há registros de debates em relação à instituição da reserva de vagas na UFPI, salvo sobre sua aprovação no CEPEX (PEDROSA, 2006, p. 2).

Assim, essa foi uma iniciativa exclusiva da administração superior da UFPI. Como diz o Reitor na entrevista, essa "foi uma decisão endógena da própria administração superior que levou isso para o CEPEX; foi uma iniciativa da nossa gestão" motivada, como consta nos registros das reuniões em que foi aprovada, e nas entrevistas, pelos seguintes fatores: exclusão dos egressos da escola pública dos cursos mais concorridos da UFPI, constatada em estudo encomendado pela Reitoria junto à COPEVE, e adoção do sistema de cotas em outras instituições públicas de ensino superior. 
Não descarta-se, contudo, o interesse do governo na matéria, do qual "a UFPI, como instituição pública federal, não poderia se furtar", disse na entrevista o Professor Fernando Aécio. E, acrescentou o prof. Newton Freitas, também na entrevista, os debates na Associação Nacional de Dirigentes das Instituições Federais de Ensino Superior (ANDIFES) que, em suas palavras, "teriam evidenciado a inexorabilidade da democratização da qual a Universidade Federal do Piauí não poderia se furtar".

O Reitor, então, consoante a esses depoimentos, teria, com a proposição, inserido a UFPI no 'diapasão do tempo', isto é, o ritmo que, naquele momento, embalava as instituições de ensino superior federais.

A novidade da UFPI foi não adotar, como a Universidade de Brasília, a Universidade Federal de São Paulo, a Universidade Federal do Maranhão ou a Universidade Federal da Bahia, o critério racial, mas o tipo de escola. Isso porque, conforme o Reitor, na entrevista, "o fato de o aluno ser negro não quer dizer que seja pobre".

O tema, efetivamente, sequer foi cogitado, pois, diz o Prof. Newton, em seu depoimento, "a intenção da presidência (CEPEX) e dos demais conselheiros era privilegiar os oriundos integralmente da escola pública e porque são os mais necessitados". No Piauí, complementa, "os pais que podem pagar para os filhos estudarem em escolas privadas assim o fazem, enquanto aqueles que realmente não tem condições são levados a estudar em escola pública". E essas, complementa, têm baixo desempenho, consequentemente "precisam do poder público, dos professores e de todos que fazem a educação para melhorá-las". A cor da pele, ainda ressalta, "não faria a diferença".

O critério do tipo de escola, dizem os entrevistados, evitaria contestações judiciais, além disso, disse o Prof. Saulo Brandão, presidente da COPESE, em 2008, na entrevista "dava chance a pessoas com menor nível social, o que não seria preponderante no critério racial [...] e estes estão na escolas públicas. Então, atendendo alunos das escolas públicas estar-se-ia atingindo o alvo desejado, as famílias de menor poder aquisitivo".

A medida, para alguns entrevistados, foi amplamente aceita, sendo as contestações inexistentes ou muito reduzidas. O Reitor Luiz Júnior, disse "que praticamente não houve reações contrárias à medida", e destaca em seu depoimento: 
a imprensa, para surpresa nossa, respeitou a decisão do CEPEX e a oposição à nossa gestão, quando acordou, já era tarde, isto é, já se constatava que os cotistas eram bons alunos, e a administração superior já estava munida de vastas informações de bons indicadores que desfazia qualquer tentativa de oposição à medida.

Para outros, houve reações contrárias. O relator da matéria, Prof. Newton, disse em seu depoimento que foram contra setores da comunidade universitária, "exgestores, a direção do Centro de Ciências da Saúde, o próprio ex-Reitor que era próReitor e outros ligados ao curso de Medicina foram peremptoriamente contrários, alegando que segregaria os estudantes de escolas públicas ou que não tinha apoio do Ministério da Educação (MEC)". Segundo esse informante, a oposição no curso de Medicina, dava-se porque "primeiro seriam aumentadas as vagas, que eram em torno de 50 por ano e passaria para 80 , e, dessas vagas, um percentual seria destinado para os alunos de escolas públicas que concorressem pelas cotas".

A Resolução no 93/06 - CEPEX foi alterada pela Resolução no 146/07-CEPEX, em 25 de junho de 2007, 12 meses após sua aprovação, quando da abertura de novo processo seletivo, atendendo pleito da COPEVE através do processo $\mathrm{n}^{\circ}$ 23111.007099/07-96 a fim de que fossem alterados o artigo $3^{\circ}$ e o parágrafo único do Art. $4^{\circ}$. Estes passaram a ter a seguinte redação:

Art. $3^{\circ}$ Conceder Bolsa de Ensino àqueles que efetuaram pagamento de taxa de inscrição em qualquer etapa do PSIU (modalidade gradativa ou geral) para os $5 \%$ (cinco por cento) dos candidatos selecionados às vagas que tiveram a vida escolar básica (ensino fundamental e médio), integralmente, em escola pública.

$[\ldots]$

\section{Art. $4^{0}[\ldots]$}

Parágrafo único. A política de permanência será proposta e aprovada pelo Conselho de Ensino, Pesquisa e Extensão (CEPEX), em observância aos seguintes aspectos: transporte, alimentação, residência universitária, material didático, internet, apoio didático-pedagógico, bolsa saúde, dentre outros benefícios, conforme possibilidade da UFPI e apoiada com recursos oriundos da Política Nacional de Assistência Estudantil (UFPI, 2007). 
Verifica-se que as alterações foram no sentido de estabelecer a bolsa como meio pelo qual seria concedida a isenção do pagamento da taxa e a supressão do prazo de 30 dias para a aprovação da política de permanência no CEPEX. A proposição daquelas ações complementares à reserva de vagas, apontadas no debate como imprescindíveis, agora não tinha mais prazo para ser apresentada.

Em 2008, como previsto, a medida foi avaliada. A mudança no percentual de vagas destinadas aos cotistas, na UFPI, foi decidida na $274^{\mathrm{a}}$ reunião do CEPEX realizada em 3 de julho de 2008, atendendo ao processo $n^{\circ} 23111.010077 / 08-11$, enviado ao CEPEX pelo presidente da COPEVE, Saulo Cunha de Serpa Brandão. A UFPI, a partir de então, em obediência à Resolução n ${ }^{\circ}$ 138/08-CEPEX/UFPI (UFPI, 2008b), passou a destinar $20 \%$ de suas vagas de graduação aos alunos egressos de escolas públicas.

Novamente, a expansão de vagas deu elementos à apreciação da matéria. Naquela ocasião, havia sido aprovado, no Senado Federal, o Programa de Apoio a Planos de Reestruturação e Expansão das Universidades Federais (REUNI), com a criação de "2.300 cargos efetivos de professor da Carreira do Magistério Superior e 1.075 cargos efetivos de técnico administrativos para diversas áreas para as Instituições Federais de Ensino Superior” (UFPI, 2008a, p. 107), o que favorecia a expansão da Universidade Federal do Piauí, inclusive com a instalação de um novo campus.

Além desse fator, justificavam o aumento percentual destinado às cotas os bons resultados acadêmicos alcançados pelos beneficiados com a reserva de vagas, e os incentivos do Ministério da Educação à democratização do acesso. O primeiro, em particular, conforme Newton Freitas, silenciava os opositores. "Eles", disse na entrevista, "começaram a perceber que as cotas davam resultados positivos e a favorabilidade do CEPEX à ampliação, patente na ação dos conselheiros, dobrou os recalcitrantes".

A reserva de vagas foi instituída, na UFPI, por iniciativa da administração superior estimulada pela expansão de vagas e em face da exclusão dos egressos da escola pública entre seus alunos. Também contribuiu o ambiente favorável à matéria com a adoção da medida por várias instituições públicas, inclusive federais, ou por ser esse um desejo manifesto do governo, consignado em várias outras iniciativas favorecedoras do acesso, inclusive com previsão de envio de 
Projeto de Lei ou possibilidade de constar na propalada Reforma Universitária. Isso, não se pode descartar, inspirou a ação dos agentes internos; todavia, não abarca todos os aspectos envolvidos no processo de implementação de uma ação por um agente público, no caso da UFPI.

A ação desse agente foi favorecida por fatores internos, entre os quais o desejo de incluir os mais pobres em seus cursos mais prestigiados, a possibilidade de expansão da oferta e de aquiescência do governo federal, ainda que envolvesse questionamentos quanto à legalidade. Esses fatores contribuíram para o reconhecimento de que o acesso desse segmento carecia de uma ação estatal. Isso tornava o acesso ao ensino superior pelos mais pobres um problema, consequentemente, alvo da ação dos formuladores de políticas.

\section{Conclusão}

Este estudo abordou o acesso ao ensino superior público favorecido pela reserva de vagas na Universidade Federal do Piauí, a partir de 2006, examinando sua conformação -identificação das motivações, objetivos e atores. Empreendeu-se um 'passeio' pela ação estatal, voltando aos seus primeiros movimentos, ou seja, sua inserção na agenda da Universidade.

Foi uma iniciativa da administração superior favorecida pela adoção da medida por várias instituições públicas, inclusive federais, pelo desejo manifesto do governo, consignado em outras iniciativas favorecedoras do acesso, inclusive com inclusão da matéria nos projetos de lei de criação das novas universidades e, principalmente, pela disponibilidade de vagas, decorrente das ações expansionistas.

Esses fatores se juntaram dando forma particularà ação da UFPI, os compromissos políticos de sua administração superior expresso, naquele momento, no slogan "Educação, Ciência, Arte e Inclusão Social", e levantamentos sobre aqueles que tinham acesso a suas vagas. Esses, por si só, indicativos de que a exclusão dos mais pobres, referenciados pela escolaridade básica realizada em estabelecimentos públicos, já era reconhecida como uma problemática que demandava ação estatal e, por conseguinte, integrante de sua agenda.

Assim, se, por um lado, a ação foi incluída na agenda quando havia condições para a sua implementação, por outro, sua formulação dependeu do 
reconhecimento do problema, da existência de soluções viáveis e aceitáveis, e clima político para adotá-las. Para isso, contou com agentes dispostos a investir em sua implementação, em particular aqueles que, naquele momento, ocupavam posições privilegiadas no espaço institucional.

Os resultados, examinados na pesquisa, também mostraram que a ação institucional dependeu de agentes dispostos a dela usufruir: alunos e cidadãos super selecionados não apenas pela prolongada escolarização, mas também por terem o ethos requerido para permanecer no ensino superior e concluir o curso. A reserva de vagas favoreceu o acesso, mas os beneficiados enfrentam dificuldades para permanecer e concluir o curso na duração prevista, pois, oriundos de famílias com renda de até 3 salários mínimos e escasso capital cultural, dependiam da assistência estudantil e apoio pedagógico previstos mas não efetivados.

Portanto, a reserva de vagas instituída pela UFPI, em 2006, favoreceu o ingresso dos alunos de escolas públicas, nos diversos cursos da instituição, não mais apenas naqueles menos concorridos. Todavia, sem o complemento da assistência estudantil e pedagógica, dependeu da disposição dos agentes beneficiados para produzir os efeitos desejados: acesso, permanência e sucesso escolar.

\section{Referências}

BITTAR, M.; ALMEIDA, C. E. M. Mitos e controvérsias sobre a política de cotas para negros na educação superior. Educar em Revista, Curitiba, n. 28, p. 141-159, jul./2006. Disponível em: <http://www.scielo.br/pdf/er/n28/a10n28>. Acesso em: 25 abr. 2012.

BRANDÃO, C. da F. As cotas na universidade pública brasileira: será esse o caminho? Campinas (SP): Autores Associados, 2005. (Coleção polêmicas do nosso tempo, 92).

BRASIL. Lei $\mathrm{n}^{\circ}$ 8.112, de 11 de dezembro de 1990. Dispõe sobre o regime jurídico dos servidores públicos civis da União, das autarquias e das fundações públicas federais. Diário Oficial da União, Brasília, 12 dez. 1990. Disponível em: <http://www.planalto.gov.br/ccivil_03/leis/18112cons.htm>. Acesso em: 28 nov. 2012. 
BRASIL. Lei $\mathrm{n}^{\circ}$ 10.172, de 9 de janeiro de 2001. Aprova o Plano Nacional de Educação e dá outras providências. Diário Oficial da União, Brasília, 10 jan. 2001. Disponível em: <http://www.planalto.gov.br/ccivil_03/leis/leis_2001/ 110172.htm>. Acesso em: 28 nov. 2012.

. Ministério do Planejamento, Orçamento e Gestão. Secretaria de Planejamento e Investimentos Estratégicos. Plano plurianual 2004-2007: mensagem presidencial. Brasília, DF, 2003.

- Ministério do Planejamento, Orçamento e Gestão. Secretaria de Planejamento e Investimentos Estratégicos - SPI. Relatório de avaliação do Plano Plurianual 2004-2007: exercício 2008: ano base 2007. Brasília, DF: Ministério do Planejamento, 2008. Disponível em: <http://www.planalto.gov. br>. Acesso em: 30 nov. 2012.

. Lei $\mathrm{n}^{0} 12.711$, de 29 de agosto de 2012. Dispõe sobre o ingresso nas universidades federais e nas instituições federais de ensino técnico de nível médio e dá outras providências. Diário Oficial da União, Brasília, DF, 30 ago. 2012a. Disponível em: <http://www.planalto.gov.br/ccivil_03/_Ato20112014/2012/Lei/L12711.htm>. Acesso em: 30 nov. 2012.

. Supremo Tribunal Federal. STF julga constitucional política de cotas na UnB. 2012b. [Notícias STF]. Disponível em: <http://www.stf.jus.br/>. Acesso em: 31 jan. 2013.

CAPELLA, A. C. N. Perspectivas teóricas sobre o processo de formulação de políticas Públicas. BIB, São Paulo, n. 61, p. 25-52,1 semestre de 2006.

COTAS raciais: reparação histórica ou separatismo? Jornal O DIA, Teresina , p. 3-5, maio 2005. (Caderno Debates).

EDUCAFRO. Mapa das ações afirmativas. 2012. Disponível em: <http:/www. educafro.org.br/>. Acesso em: 30 mai. 2013.

FERNANDES, A. UFPI receberá R \$ 10 milhões para expansão. Jornal O DIA, Teresina, p. 3, 28 dez. 2005. (Caderno Dia-a-dia). 
GOMIDE, A. A. Agenda governamental e o processo de políticas públicas: o projeto de lei de diretrizes da política nacional de mobilidade urbana. Texto para Discussão, Brasília, DF IPEA, n. 1334, p. 7-24, 2008.

IPAE. Instituto de Pesquisas Avançadas em Educação. Considerações acerca do sistema de cotas no Brasil. Estudo Técnico. Rio de Janeiro, jun. 2010.

IBGE. Síntese dos indicadores sociais: uma análise das condições de vida da população brasileira 2010. Estudos e Pesquisas, Rio de Janeiro, n. 27, 2010. Disponível em: <http://www.ibge.gov.br>. Acesso em: out. 2012.

PASSOS, G. de O. Educação superior e reprodução das desigualdades sociais: estudo sobre o acesso à universidade pública. Teresina, 2007. Projeto de Pesquisa apresentado ao Programa de Bolsa de Iniciação Científica - PIBICUFPI/CNPq.

. Acesso ao ensino superior público: democratização e desigualdades sociais na Universidade Federal do Piauí. Teresina, 2009. Projeto de Pesquisa apresentado ao Programa de Bolsa de Iniciação Científica - PIBIC-UFPI/CNPq.

PEDROSA, R. UFPI adota cota para aluno da rede pública. Jornal O Dia, Teresina, p. 2, 10 jun. 2006. (Caderno Política).

PINTO, J. M. de R. O acesso à educação superior no Brasil. Educação e Sociedade, Campinas (SP), v. 25, n. 88 - Especial, p. 727-756, out., 2004. Disponível em: $<$ http://www.cedes.unicamp.br $>$. Acesso em: 30 nov. 2010.

QUEIROZ, D. M.; SANTOS, J. T. do. Sistema de cotas: um debate. Dos dados à manutenção de privilégios e de poder. Educação e Sociedade, Campinas (SP), v. 27, n. 96 - Especial, p. 717-737, out., 2006. Disponível em <http://www. cedes.unicamp.br>. Acesso em: 30 nov. 2010.

RISTOFF, D. I.; PACHECO, E. Educação superior: democratizando o acesso. Brasília, DF: Instituto Nacional de Estudos e Pesquisas Educacionais Anísio Teixeira, 2004. 
UFPI. Universidade Federal do Piauí. Comissão Permanente de Vestibular - COPEVE. Processo $N^{o}$ 23.111.6484/06-81. Solicitação de aprovação de Proposta de Atualização da Resolução No. 077/2000-CEPEX que "Normatiza o Programa Seriado de Ingresso na Universidade - PSIU". Teresina, 19 mai. de 2006a.

.251 ${ }^{\mathrm{a}}$ Reunião do Conselho de Ensino, Pesquisa e Extensão. 2006. Ata. Teresina: UFPI, 25 mai. 2006b.

. 252 Reunião do Conselho de Ensino, Pesquisa e Extensão. 2006. Ata. Teresina: UFPI, 06 jun. 2006c.

UFPI. Universidade Federal do Piauí. 253 ${ }^{\mathrm{a}}$ Reunião do Conselho de Ensino, Pesquisa e Extensão. 2006. Ata. Teresina: UFPI, 14 jun. 2006d.

- Resolução 093/06-CEPEX/UFPI. Teresina: Conselho de Ensino Pesquisa e Extensão - CEPEX, 2006e.

UFPI. Universidade Federal do Piauí. Resolução 146/07-CEPEX/UFPI. Teresina: Conselho de Ensino Pesquisa e Extensão - CEPEX, 2007.

. 274 Reunião do Conselho de Ensino, Pesquisa e Extensão. Ata. Teresina: UFPI, 3 jul. 2008a.

- Resolução 138/08-CEPEX/UFPI. Teresina: Conselho de Ensino Pesquisa e Extensão - CEPEX, 2008b.

UNIVERSIDADE aberta será instalada no Piauí. Jornal O Dia, Teresina, p. 2, 01 jan. 2006. (Caderno Política). 


\section{The implementation of quotas in brazilian public university: the intricacies of policy formulation Abstract}

This paper addresses the access to the Brazilian public Higher Education. In analyzing motivations, goals and stakeholders, the work aims to characterize the implementation of quotas at the Federal University of Piaui, emphasizing its inclusion in the agenda; the establishment of alternative solutions and the policy formulation. The study is based on Multiple Streams Model, documentary sources and interviews with the University President; process rapporteurs, prosecutors, provost and the presidents of the Student Admission Standing Committee (Comissão Permanente do Vestibular - COPEVE). It concludes that quotas have been initiated by the university central administration and stimulated by the vacancies growth. In addition, due to the exclusion of students from public primary and secondary schools into the most competitive university courses. Therefore, the formulation has depended on the problem recognition; the existence of viable and acceptable solutions, demand as well as favorable political climate, additionally by the agents actions inclined to implement the program.

Keywords: Higher Education. Public Schools. Public Policy Analysis. Quota Admissions.

\section{La institución de la reserva de plazas en la universidad pública brasileña: los meandros de la formulación de una política}

\section{Resumen}

Se aborda el acceso a la enseñanza superior pública en Brasil, se analiza la institución de las cuotas en la Universidad Federal de Piaui en términos de motivaciones, objetivos y actores involucrados. Se objetiva caracterizar la experiencia, enfatizando la inserción en la agenda, el establecimiento de las alternativas de solución y la formulación de la política. Para tal, se basa en el modelo de Múltiples Flujos, en fuentes documentales y entrevistas con el Rector, relator del proceso, procuradores, asesores del rector y presidentes de la COPEVE - Comisión Permanente de la Selectividad en Brasil. Se constató que ésta fue una iniciativa de la administración superior estimulada por la expansión de plazas y por la exclusión de los egresados de la escuela pública en los cursos más pedidos de la Universidad. Por lo tanto, la formulación dependió del reconocimiento del problema y de la existencia de soluciones posibles y aceptables, demanda y situación política favorable; $y$, principalmente, de agentes dispuestos a actuar para su concretización.

Palabras clave: Educación Superior. Escuela Pública. Análisis de política pública. Reserva de Plazas. 